\title{
Dynamic Response of a Conceptual Designed Articulated Offshore Wind Turbine
}

\section{Pei Zhang ${ }^{1}$}

State Key Laboratory of Hydraulic Engineering Simulation and Safety, Tianjin University Tianjin, 300350, China

E-mail: zhangpei_ch@tju.edu.cn

\section{Yan Li}

State Key Laboratory of Hydraulic Engineering Simulation and Safety, Tianjin University Tianjin, 300350, China

Tianjin Key Laboratory of Port and Ocean Engineering, Tianjin University

Tianjin, 300350, China

E-mail: liyan_0323@tju.edu.cn

\section{Jiayang Gu}

Institute of Marine Equipment Research, Jiangsu University of Science and Technology Zhenjiang, Jiangsu, 212003, China

E-mail: gujiayang@126.com

\section{Tianchang Yin}

State Key Laboratory of Hydraulic Engineering Simulation and Safety, Tianjin University Tianjin, 300350, China

Tianjin Key Laboratory of Port and Ocean Engineering, Tianjin University

Tianjin, 300350, China

E-mail: 1402406607@qq.com

\section{Zhiqiang Hu}

School of Engineering, Newcastle University

Newcastle upon Tyne, NE1 7RU, United Kingdom

E-mail: zhiqiang.hu@ncl.ac.uk

\section{Yougang Tang}

State Key Laboratory of Hydraulic Engineering Simulation and Safety, Tianjin University Tianjin 300350, China

E-mail: tangyougang_td@163.com

\footnotetext{
1 Corresponding authors: Yan Li, E-mail: liyan_0323@tju.edu.cn; Jiayang Gu, E-mail: gujiayang@126.com
} 


\begin{abstract}
Focusing on the 75-meter-depth offshore area, an articulated foundation is proposed for supporting NREL 5 MW offshore wind turbine. Through the overall sensitivity check on hydrostatic performance, the main parameters are set to meet the requirements of stability and economy. An in-house code was programmed to simulate the dynamic response of the articulated offshore wind turbine. The aerodynamic load on rotating blades and the wind pressure load on tower are calculated based on the blade element momentum theory and the empirical formula, respectively. The hydrodynamic load is simulated by the 3-D potential flow theory. The motions of foundation, the aerodynamic performance of the wind turbine and the loads on the articulated joint are documented in different cases. According to the simulations, the articulated offshore wind turbine shows feasibility to work in the particular area.
\end{abstract}

Keywords: articulated offshore wind turbine, sensitivity check, stability, hydrodynamics, dynamic response.

\title{
[1] INTRODUCTION
}

At present, more and more attention has been paid to the research of offshore renewable energies [1,2]. According to the latest statistic data, the worldwide installed offshore wind power capacity in 2019 was $6.98 \mathrm{GW}$, and the cumulative installed capacity was $27.21 \mathrm{GW}, 25$ times more than that value in 2007. Typically, there are two main types of foundations to support offshore wind turbines (OWTs). One is fixed, the other is floating. The former ones are mainly used for water depth less than 50 meters [3]. On the other hand, the latter foundations could be more suitable for deep-water areas. Their stability and dynamic performance have been validated, according to experimental and numerical investigations [4,5].

Due to seafloor landscape, the average water depth of the southeastern China coastal area is about 50 to 80 meters. However, there are few available foundations within this depth range in consideration of the design factors, including economic cost, technical difficulty, and safety, etc. Towards this end, we proposed an articulated offshore wind turbine (AOWT) based on the articulated oil and gas $(\mathrm{O} \& \mathrm{G})$ platform. As one kind of classical platform, its feasibility has been validated in many offshore projects [6-7]. Meanwhile, some researches have been conducted to further investigate its dynamics under different scenarios. For example, Zaheer and Islam [8] established a two-DOF analytical model to investigate the motion of a double-hinged articulated tower. Javed [9] studied the seismic influence on the hydrodynamic performance of a single-hinged articulated tower. 
The relevant research on AOWTs is still in the premilitary stage. Wu et. al [10] proposed a single-articulated offshore wind turbine, which was applicable to $90 \mathrm{~m}$ water depth. Similarly, Philip et. al [11] conceptually designed a three-leg-hinged foundation for 5MW offshore wind turbine. Joy et. al [12] conducted a 1:60 scale experiments on the three-leg hinged 5MW wind turbine. According to these investigations, the availability of AOWTs is initially validated.

In this study, a single-degree-of-freedom rigid body analysis model of AOWT is developed. The hydrostatic performance is firstly checked under different structural dimensions. Based on the potential flow theory, the wave-body interaction is calculated with stochastic waves. The aerodynamic loads on rotating blades are calculated by the blade element momentum theory. Besides, the friction damping of the articulated hinge is also taken into consideration. According to these models, the dynamic response under complicated scenarios are simulated, and the results, including platform motion, output power and tension in the hinge, are further displayed and discussed.

\section{[2] PHYSICAL PROBLEM DESCRIPTION}

As is shown in Fig.1(a), the AOWT mainly consists of the NREL 5MW baseline wind turbine and an articulated support foundation. Detailed parameters of the wind turbine could be easily found from previous work or other similar researches [13]. On the one hand, the support foundation consists of a perforated column, a buoyancy tank and a ballast tank. The configuration of the articulated foundation is shown in Table 1. Hereby, $(x, y)$ is a two-dimension Cartesian coordinate system with its origin at the hinge point on the sea floor and $y$ axis pointing upward, see Fig.1(b). The $x$ axis coincides with the direction of the incoming wind and wave.

Fig.1 Articulated offshore wind turbine

Table 1 Main parameters of the AOWT

\section{[3] METHODOLOGY}

\subsection{Static analysis for preliminary design}

In order to achieve the balance between safety and economic cost, a series of static analyses are established to conduct sensitivity check on the diameters of each tank and column. By adopting the control variable method, the ratio of restoring moment to wind heeling moment is set as the objective function. Hereby, the objective function $u$ is defined as,

$$
u=f\left(D, D_{1}, D_{2}\right)=M_{R} / M_{W},
$$

where $D$ is the diameter of the column, $D_{1}$ is the diameter of ballast tank, and $D_{2}$ represents the diameter of the buoyancy tank. $M_{R}$ is the restoring moment of the whole structure. The hydrostatic restoring moment under $5^{\circ}$ trim angle is integrated on the submerged body. On the other hand, $M_{w}$ denotes the wind heeling moment at the rated condition, while the thrust on the rotor is calculated 
based on the blade element momentum algorithm and the wind pressure on the tower is calculated based on the empirical equation.

The main constraint in present analysis is that the restoring moment should be greater than the wind heeling moment. In other words, it means that the objective function should be more than 1. Besides, the initial force on the articulated joint should not exceed the safety limitation [14]. After these safety conditions are satisfied, the total steel usage amount could be then optimized in the detailed design stage, in order to reduce the manufacture cost.

\subsection{Dynamic analysis and corresponding governing equations}

After the initial parameters are finalized in the static analysis, the dynamic analysis will be taken into consideration in time domain. The major aim of time-domain analysis is to show the dynamic response of the system under the complicated wind-wave-current sea states, considering the aero-hydro-motion coupling effect. Specifically, in this study, the incident flow, including wind, wave and current, are assumed in collinear direction. Because of the articulated hinge on the seafloor, the dominate motion of AOWT will be the pitch rotation about the joint. Based on the dynamic equation of articulated platform motion [15], the governing equation of the AOWT is further derived and established in time domain as following,

$$
\left(I+I_{\infty}\right) \ddot{\theta}+\int_{0}^{t} h(t-\tau) \dot{\theta}(\tau) d \tau+C \dot{\theta}+M_{f r}(\dot{\theta})+M_{g b}(\theta)=q(\theta, \dot{\theta}),
$$

where $h(t)$ is the retardation function, $I$ represent the moment of inertia and $I_{\infty}$ is the added mass when the frequency approaches infinite, $C$ is the viscous damping on the foundation. Based on the previous study on offshore structures [16], 5\% of critical damping is adopted to represent this effect. $M_{f r}(\dot{\theta})$ denotes the friction damping moment of articulated joint, $M_{g b}(\theta)$ is the restoring moment, $\theta, \dot{\theta}, \ddot{\theta}$ denote the pitch angle, angular velocity and angular acceleration respectively. $q(\theta, \dot{\theta})$ are external environmental loads, including the wave and current loads on the submerged foundation, the aerodynamic loads on the rotor, and the wind pressure on the tower. By adopting the fourth-order Runge-Kutta algorithm, the differential equation is numerically solved in every time step, and dynamic responses could be documented in time domain.

\subsection{Friction Damping and Restoring Force}

For spherical articulated joint, the friction damping moment could be obtained from the following formula [17], 


$$
\left.\begin{array}{l}
M_{f r}=\mu N R[\operatorname{sign}(\dot{\theta})] \\
N=\sum N_{x}+\sum N_{y} \\
\sum N_{x}=M \omega^{2} h_{g} \sin (\theta)-M a h_{g} \cos (\theta)+Q_{x} \\
\sum N_{y}=\left(F_{\text {buoy }}-M g\right)+M \omega^{2} h_{g} \cos (\theta)+M a h_{g} \sin (\theta)+Q_{y}
\end{array}\right\},
$$

where $\mu$ is the friction coefficient, and 0.1 is adopted based on the experience. $R$ is the radius of the spherical articulated joint, and $1.5 \mathrm{~m}$ is adopted, $\operatorname{sign}(\dot{\theta})$ represents the unit vectors in the same direction as angular velocity vectors. $N$ denotes the reaction force, it can be divided into two parts, $N_{x}$ in $x$ direction and $N_{y}$ in $y$ direction. $M$ is the total mass, $\theta, \omega, a$ represent the pitch angle, angular velocity, and angular acceleration respectively. $h_{g}$ is the height of center of gravity relative to the hinged joint, $F_{\text {buoy }}$ represents the buoyancy, $Q_{x}$ represents the external environmental loads in the $x$ direction, including the thrust on the rotor, wind pressure on the tower, wave load and current load in the surge direction. $Q_{y}$ represents the environmental forces in the heave direction.

On the other hand, the restoring moment is calculated by the relationship between the moments provided by buoyancy and gravity, as following,

$$
M_{R}=F_{\text {buoy }} l_{b}-M g l_{g},
$$

where $l_{b}$ is the moment arm of buoyancy to the hinged joint, $l_{g}$ is the moment arm of gravity to the hinged joint.

\subsection{Environmental Loads}

\subsubsection{Wind Load}

The wind loads on the wind turbine include the aerodynamic load on the rotor and the wind pressure load on the tower. The aerodynamic load is calculated based on the blade element momentum theory [18]. The axial thrust and torque on each blade element are,

$$
\begin{aligned}
d T & =\frac{1}{2} \rho V^{2} B c\left(C_{l} \cos \varphi+C_{d} \sin \varphi\right) F d r, \\
d M & =\frac{1}{2} \rho V^{2} B c\left(C_{l} \sin \varphi-C_{d} \cos \varphi\right) F r d r,
\end{aligned}
$$

where $\rho$ is the air density, $V$ is the resultant wind speed, $B$ is the number of blades, $c$ is the chord length of the blade element, $C_{l}$ and $C_{d}$ are the lift and drag coefficients respectively, $\varphi$ is the inflow angle, $r$ is the distance from the local element to the hub, $d r$ is the length of the blade element, $F$ is the Prandtl tip-hub loss factor[19]. By integrating these loads along every blade, the aerodynamic loads on the rotor could be obtained.

On the other hand, the wind pressure on the tower is calculated based on the empirical formula 
recommended by CCS [20], as following shows,

$$
P_{\text {tower }}=0.613 \sum_{i=1}^{n}\left(C_{h} C_{s} A_{i}(\alpha) V_{r}^{2}\right)
$$

where $n$ is the total number of components, $C_{h}$ is the height coefficient, $C_{s}$ is the shape coefficient, $A_{i}(\alpha)$ is the projection area of the corresponding part when the wind direction angle is $\alpha, V_{r}$ is the relative wind speed.

\subsubsection{Hydrodynamic Loads}

The wave load on AOWT is calculated by three-dimensional potential flow theory, which is a classic but widely used approach in the dynamic simulation of offshore structures. In present work, the wave-body interaction is calculated based on the $3 \mathrm{D}$ potential theory in frequency domain by using the DNVGL software WADAM [21]. Then, the stochastic wave load could be generated into time series by convolutional approach. In other words, we have the wave load time histories as following shows,

$$
F_{\text {wave }}(t)=\operatorname{Re}\left[\sum_{i=1}^{M} \eta_{i} F_{1}\left(\omega_{i}\right)\right]=\operatorname{Re}\left[\sum_{i=1}^{M} a_{i} \exp \left[i\left(\omega_{i} t+\phi_{i}\right)\right] F_{1}\left(\omega_{i}\right)\right],
$$

where $\eta_{i}$ denotes the elevation of $i$-th wave component in complex domain. $F_{1}(\omega)$ is the linear transfer function. $a_{i}, \omega_{i}$ and $\varphi_{i}$ represent the amplitude, frequency, and phase of $i$-th wave component as mentioned above, respectively. Hereby, more details about algorithm and validation could be observed in our publication [22].

\subsubsection{Current Load}

Current loads on the foundation are calculated in accordance with CCS recommended practice $[20]$,

$$
F_{c u r}=\frac{1}{2} C_{D} \rho_{W} A V_{c u r}^{2}
$$

where $C_{D}$ means the drag coefficient, 0.7 is adopted based on the experience. $\rho_{w}$ is the seawater density, $A$ is the projection area of the component on the plane perpendicular to the velocity of current, $V_{\text {cur }}$ denotes the relative velocity of current.

\section{[4] RESULTS}

\subsection{Sensitivity check on the tank diameters}

According to the algorithms mention in section 3.1, the objective function is related to the column diameter $D$, the ballast tank diameter $D_{1}$ and the buoyancy tank diameter $D_{2}$. In the following analysis, $D$ are chosen in the range from $5 \mathrm{~m}$ to $15 \mathrm{~m}$ with $1 \mathrm{~m}$ increment step. Moreover, three different $\triangle D_{1}$ (difference between $D$ and $D_{1}$ ) and four different $\triangle D_{2}$ (difference between 
$D$ and $D_{2}$ )are adopted in every cases, and the results are displayed in Fig.2.

Fig. 2 Objective function value in the case of different column diameters

According to the results in Fig.2, both column diameter $D$ and the buoyancy tank diameter $D_{2}$ should be large enough to provide stability, due to the requirement that $u$ should be larger than one. On the contrary, large ballast tank diameter $D_{1}$ has negative influence on the restoring moment, but this effect is much lower than that of $D_{2}$. To save the steel usage, the cases that $D$ equals $6 \mathrm{~m}$ are chosen to perform the following checks. At the same time, when $\triangle D_{2}$ is larger than $10 \mathrm{~m}$, the value $u$ basically satisfies the requirement, then we locally analyze the influence of diameter $\mathrm{D}_{2}$ on the initial joint tension and steel usage in the zoomed-in range from $16 \mathrm{~m}$ to $20 \mathrm{~m}$. As $D_{1}$ is less sensitive to the system, the middle value $\triangle D_{1}=3 \mathrm{~m}$ is fully qualified, so $D_{1}=9 \mathrm{~m}$ is adopted in the following simulations

Fig. 3 Sensitivity check on $\mathrm{D}_{2}$

The results about the sensitivity check on $\mathrm{D}_{2}$ are shown in Fig.3. When $\mathrm{D}_{2}$ equals $18 \mathrm{~m}$, the value of objection function will exceed 1.0. Based on the results in Fig.3(b) and (c), we find both steel usage and articulated joint force are positively correlated with $\mathrm{D}_{2}$. Based on these results, main parameters are determined and the following dynamic simulations will be carried out.

\subsection{Free Decay Analysis}

In order to find the natural frequency of the pitch motion, the free decay analysis is conducted. By adopting an initial trim angle and setting it free, the pitch motion time history is documented in Fig. 4(a), and the response spectrum is calculated by Fast Fourier Transformation in Fig. 4(b).

Fig. 4 Free decay simulation results

According to results, the natural frequency of pitch motion is $0.233 \mathrm{rad} / \mathrm{s}$. In other words, the natural period of AOWT is $26.95 \mathrm{sec}$, which avoids common wave periods (conventional range comes from $5 \mathrm{sec}$ to $20 \mathrm{sec}$ ). On the other hand, the rated speed of NREL 5MW wind turbine is $12.1 \mathrm{rpm}$, so the $1 \mathrm{P}$ frequency of aerodynamic load is $1.27 \mathrm{rad} / \mathrm{s}$, while the $3 \mathrm{P}$ frequency is 3.80 $\mathrm{rad} / \mathrm{s}$. The natural frequency also avoids both $1 \mathrm{P}$ and $3 \mathrm{P}$ rotating frequencies.

\subsection{Dynamic response under operation conditions}

Three different conditions under the operational sea state are defined as Table 2 shows. Specifically, JONSWAP spectrum is adopted to generate the irregular wave elevations in the simulation. Among the results, we focus on the pitch motion of the structure, as well as aerodynamic performance and hinged joint tensions.

Table 2 List of scenarios

In the following simulations, the total duration is $3600 \mathrm{sec}$, and the time step is $0.1 \mathrm{sec}$. After 
the first $600 \mathrm{sec}$ of initial start-up oscillations, the rest samples (30000) are adopted for results analysis, including data statistics and FFT post-processing. Hereby, the statistic results are shown in Fig.5, and more details, including the motion, aerodynamic performance and tensions on hinged joint will be further discussed in the following subsections.

Fig. 5 Statistic results of motions, aerodynamic performance and hinged joint tensions

\subsubsection{Pitch motion of foundation}

Fig. 6 Dynamic response of pitch angle

The time histories and response spectra of pitch motion are displayed in Fig.6. Based on the statistic results in Fig.5(a) and the time histories in Fig.6(a), we see that the mean pitch angle will reach the maximum under the rated sea state (LC2). This phenomenon is caused by the maximum thrust on the rotor when the AOWT works under the rated wind speed, which is influenced by many factors, including wind speed, blade pitch angle, foundation motion, etc. Although the wind speed in LC3 exceeds that in LC2, the blade pitch angle controlling system will switched on to maintain the output power in the rated level, and the thrust will be reduced.

On the other hand, the standard deviation increases from LC1 to LC3. The standard deviation is a representative of the oscillation amplitude around the new equilibrium position. According to the spectra in Fig.6, there are three peaks in the spectra, which correspond to natural frequency, wave frequency and $1 \mathrm{P}$ rotating frequency respectively. To be specific, due to the lower rotating speed in LC1, the largest amplitude corresponds to the 1P frequency which is smaller than that value in LCs 2 and 3. Besides, it shows that the dominate oscillation is wave-frequency component. In other words, the higher wave will amplify dynamic fluctuations of AOWT, in terms of the larger wave load.

\subsubsection{Aerodynamic performance}

Fig. 7 Aerodynamic performance of rotor

The time histories and spectra of rotor aerodynamic performance are shown in Fig.7. It can be seen from Fig.7(a) that the thrust on the rotor has similar variations among the three cases with those of foundation pitch motion. In other words, the largest thrust occurs in the rated case. This is another factor shows the coupling effect between aerodynamics and motion. Moreover, according to Fig.7(c), we see that the output power could remain at 5MW when the wind speed exceeds the rated level and the blade pitch controlling system is switched on in LC3. In other words, the wind turbine could work safely and normally under these scenarios.

According to the response spectra in Fig.7(b), it shows that peaked frequencies are in parallel with those components in the pitch motion response spectra. The similar phenomenon is also 
observed in Fig.7(d), the output power spectra. However, there are some differences existing among the results. It could be seen in Fig.7(d) than the dominate wave-frequency response in LC3 is smaller than that in LC2, unlike the phenomenon shows in the pitch motion spectra in Fig.6(b). It is contributed by the increased blade pitch angle in the high wind speed case. Therefore, the drag force on the blade, as well as aerodynamic damping, is amplified by the pitch angle, so the responses are decreased.

\subsubsection{Tension on hinged joint}

Fig. 8 Tensions on the hinged joint

The tension on articulated hinge are displayed in Fig.8. From the results in Fig.5(d) and Fig.8(a), when the wind speed increases, the average value of tension in X-direction increases gradually, and reaches the maximum at the rated wind speed, like thrust and pitch motion. Besides, according to Fig.5(e) and Fig.8(c), it is found that the average value of Y-direction tension remains at the same level among the cases. This is due to the factor that the Y-direction tension represents the remaining buoyancy after the abrupt change by wave. However, unlike the response spectra of motion and aerodynamic performance, the only dominate component in the spectra in Fig.8(b) and (d) is the wave-frequency response, and the increasing trend is also observed from LC1 to LC3. It means that the wave load is the most significant influence on the articulated tension.

\section{[5] CONCLUSIONS}

In present work, an AOWT was adopted in the $75 \mathrm{~m}$-depth area. According to static calculation, the sensitivity of foundation diameters is firstly checked, and the dynamic features are then simulated in time domain. Based on the results, we initially validated its feasibility to working in this area.

Specifically, both tank diameters and column diameter are determined based on the static approach. Considering the aerodynamics, hydrodynamics and the coupling effect, a SDOF rigid body analysis model of the AOWT was established in time domain. According to the relaxation tests, the natural frequency of pitch motion avoids the wave frequency, the 1P frequency. In other words, there will be few resonance effects for the system during the normal operations. The dynamic performance under different scenarios are also investigated, and the responses, including pitch motion, aerodynamic performance and articulated joint tensions, show its satisfactory behavior under the operational cases.

However, it is necessary to point out that in the current AOWT is conceptually and initially designed. There still exist some potential issues to be studied in the future. Firstly, the dynamic performances of AOWT in turbulent wind flow is not include in present work. Besides, the validation of our in-house code is based on those on each separate module. At present, a aerodynamic DLL-plugin is being established under ANSYS-AQWA, in order to conduct the 
numerical validation. Moreover, we are planning to conduct a series of 1/50 experimental tests to investigate the hydrodynamic and structural dynamic performance. Moreover, the design of specified hinged joint, better geometric modelling constraints [23] about articulated joint and cost analysis of the system will also be done in the following works.

\section{ACKNOWLEDGMENTS}

This work is financially supported by the Natural Science Foundation of China (Grant No. 51879188 and 51779109), the Natural Science Foundation of Jiangsu Province (BK20171306), the Project funded by China Postdoctoral Science Foundation (No.2019M651042) and the Innovative Foundation of Tianjin University (No. 2006)

\section{REFERENCE}

[1] Stock-Williams, C., \& Swamy, S. K. (2019). Automated daily maintenance planning for offshore wind farms. Renewable Energy, 133, 1393-1403.

[2] Zhang, Y., Zhang, J., Lin, X., Wang, R., Zhang, C., \& Zhao, J. (2020). Experimental investigation into downstream field of a horizontal axis tidal stream turbine supported by a mono pile. Applied Ocean Research, 101, 102257.

[3] Whiteman A., Esparrago J., Elsayed S. et.al, (2018). Renewable Energy Statistics 2018, International Renewable Energy Agency.

[4] Li, L., Liu, Y., Yuan, Z., \& Gao, Y. (2019). Dynamic and structural performances of offshore floating wind turbines in turbulent wind flow. Ocean Engineering, 179, 92-103.

[5] Jijian Lian, Junni Jiang, Xiaofeng Dong, Huan Zhou, Pengwen Wang. Coupled Motion Characteristics of Offshore Wind Turbine during the Integrated Transportation Process. Energies. 2019, 12(10), 2023:1-23.

[6] Nagamani, K., \& Ganapathy, C. (1996). Finite element analysis of nonlinear dynamic response of articulated towers. Computers \& Structures, 59(2), 213-223.

[7] Gavassoni, E., Gonçalves, P. B., \& de Mesquita Roehl, D. (2015). Nonlinear vibration modes of an offshore articulated tower. Ocean Engineering, 109, 226-242.

[8] Zaheer, M. M., \& Islam, N. (2017). Dynamic response of articulated towers under correlated wind and waves. Ocean Engineering, 132, 114-125.

[9] Javed, S. Y. (2018). Near Fault Effect on the Response of Single Hinged Compliant Offshore Tower. In MATEC Web of Conferences (Vol. 203, p. 01015). EDP Sciences.

[10] Wu, H. T., Zhang, L., Zhao, J., \& Ye, X. R. (2012). Primary Design and Dynamic Analysis of an Articulated Floating Offshore Wind Turbine. In Advanced Materials Research (Vol. 347, pp. 2191-2194). Trans Tech Publications.

[11] Philip, V., Joseph, A., \& Joy, C. M. (2015). Three-legged articulated support for 5 MW offshore wind turbine. Aquatic Procedia, 4, 500-507.

[12] Joy, C. M., Joseph, A., \& Mangal, L. (2016, June). Experimental investigation on the dynamic response of a three-legged articulated type offshore wind tower. In ASME 201635 th International Conference on Ocean, Offshore and Arctic Engineering (pp. V001T01A009-V001T01A009). American Society of Mechanical 
Engineers.

[13] Navin.S.S, Vivek Philip. (2016) Fatigue Analysis of Articulated Support for Offshore Wind Turbine. International Research Journal of Engineering and Technology, 04(06): 2266-2271.

[14] Spherical bearing for bridges. (GB/T 17955) Standardization law of the people's republic of china. Communications Press: Beijing, China, 2009. (In Chinese).

[15] Xie, W.; Tang, Y.; Zhou, M. Nonlinear dynamic characteristic analysis of articulated tower platform in the deep water. Eng. Mech. 2006, 23, 36-41+119 (In Chinese).

[16] Tao L B. Viscous damping of TLP and Spar in deep water. Shipbuild. China2006 (02): 21-27. (In Chinese).

[17] Zhou MH. Analysis of nonlinear dynamics response of an articulated tower platform. M. S. Eng Dissertation in Tianjin University,2005. (in Chinese).

[18] Moriarty, P.J.; Hansen, A.C. AeroDyn Theory Manual (No. NREL/TP-500-36881); National Renewable Energy Lab.: Golden, CO, USA, 2005.

[19] Li, Y., Liu, L., Zhu, Q., Guo, Y., Hu, Z., \& Tang, Y. (2018). Influence of vortex-induced loads on the motion of SPAR-type wind turbine: a coupled aero-hydro-vortex-mooring investigation. Journal of Offshore Mechanics and Arctic Engineering, 140(5), 051903.

[20] China Classification Society. Offshore mobile platform classification guidelines. Beijing, China Communications Press, 2005. (in Chinese).

[21] Lopez-Pavon C, Souto-Iglesias A. Hydrodynamic coefficients and pressure loads on heave plates for semisubmersible floating offshore wind turbines: A comparative analysis using large scale models[J]. Renewable Energy, 2015, 81:864-881.

[22] Li, L., et al. Dynamic and structural performances of offshore floating wind turbines in turbulent wind flow. Ocean Engineering, 2019. 179: p. 92-103.

[23] S. Awtar, A.H. Slocum, E. Sevincer, "Characteristics of beam-based flexure modules", J. Mech. Des., 129 (2007), pp. 625-639.

\section{Figure Captions List}

Fig. 1 Articulated offshore wind turbine

Fig. 2 Objective function value in the case of different column diameters

Fig. 3 Sensitivity check on $\mathrm{D}_{2}$

Fig. 4 Free decay simulation results

Fig. 5 Statistic results of motions, aerodynamic performance and hinged joint tensions

Fig. 6 Dynamic response of pitch angle

Fig. 7 Aerodynamic performance of rotor

Fig. 8 Tensions on the hinged joint

\section{Table Captions List}

Table. 1 Main parameters of the AOWT

Table. 2 List of scenarios 


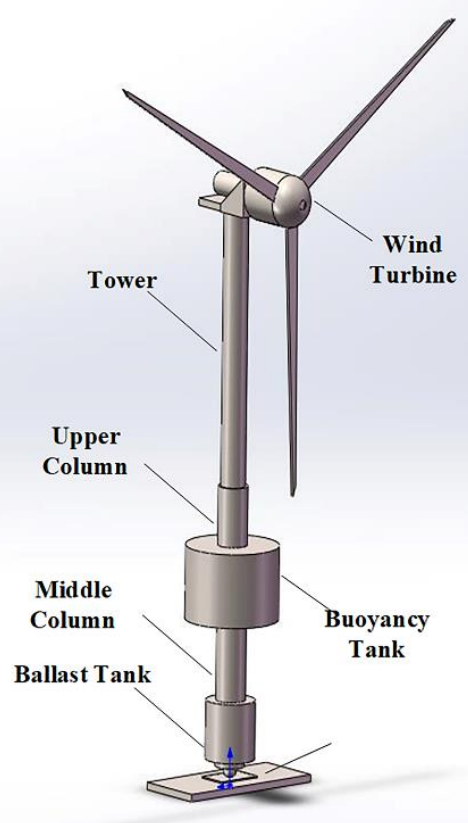

(a) Configuration

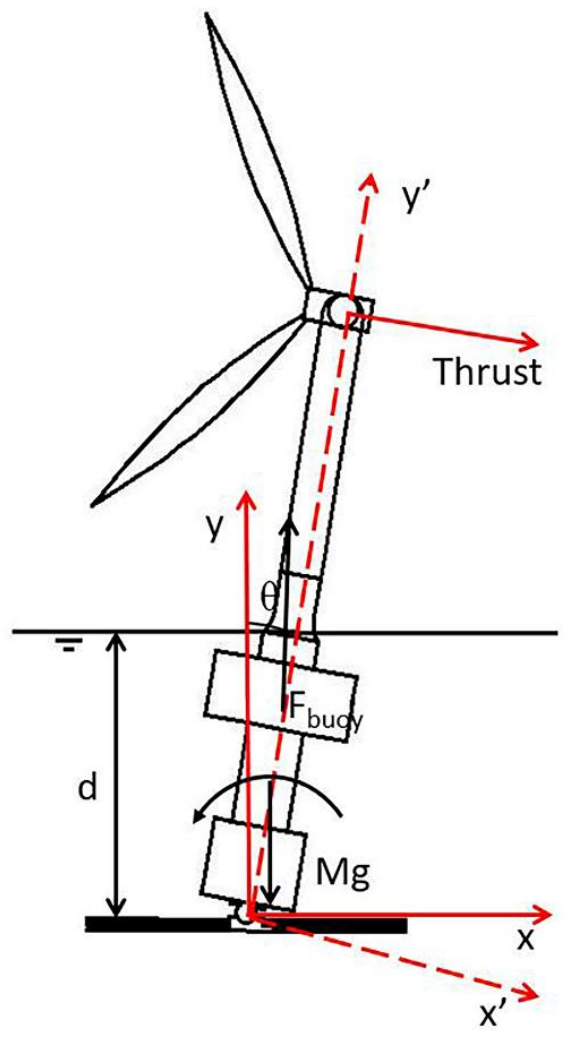

(b) Coordinate System

Fig.1 Articulated offshore wind turbine 


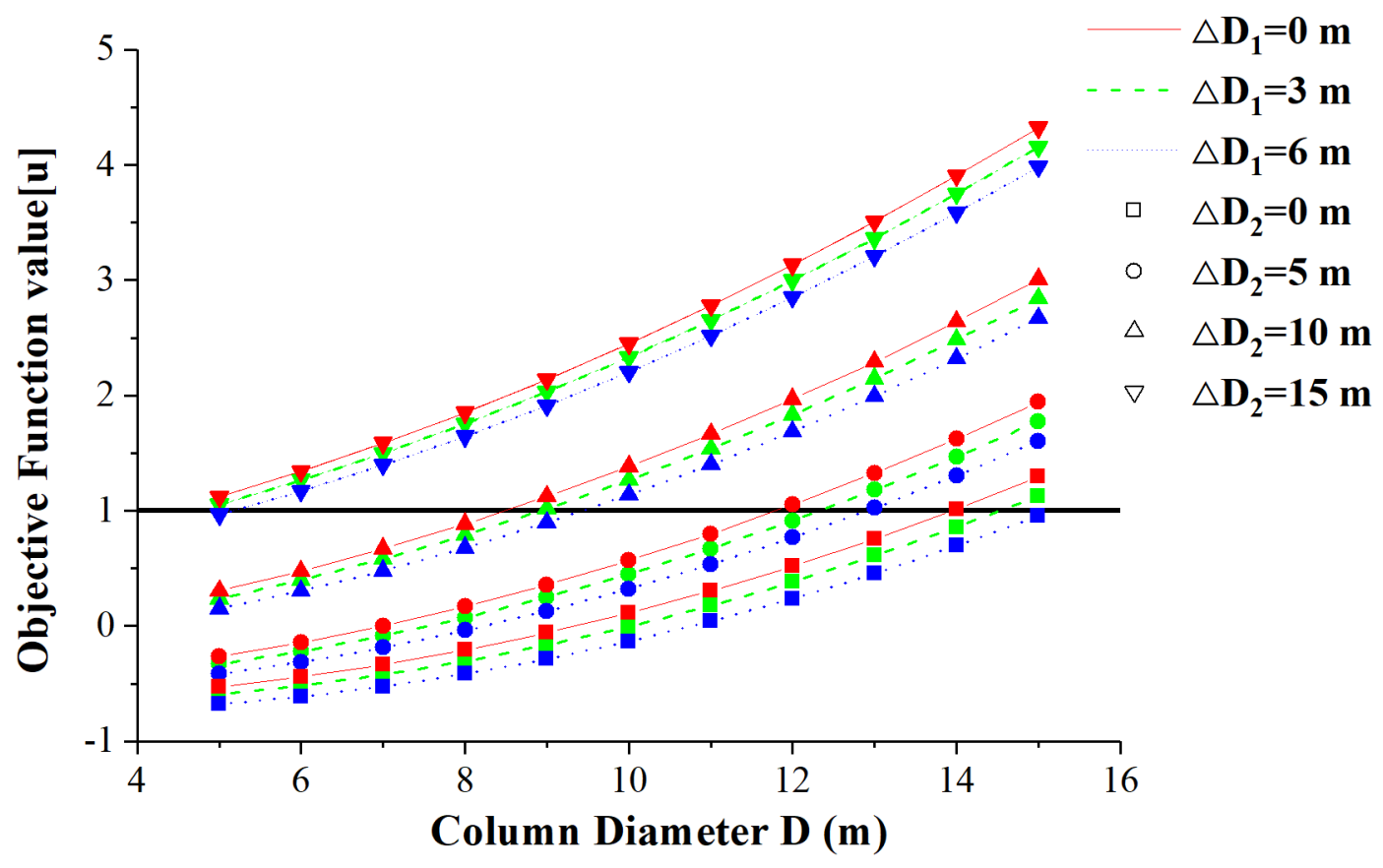

Fig. 2 Objective function value in the case of different column diameters 


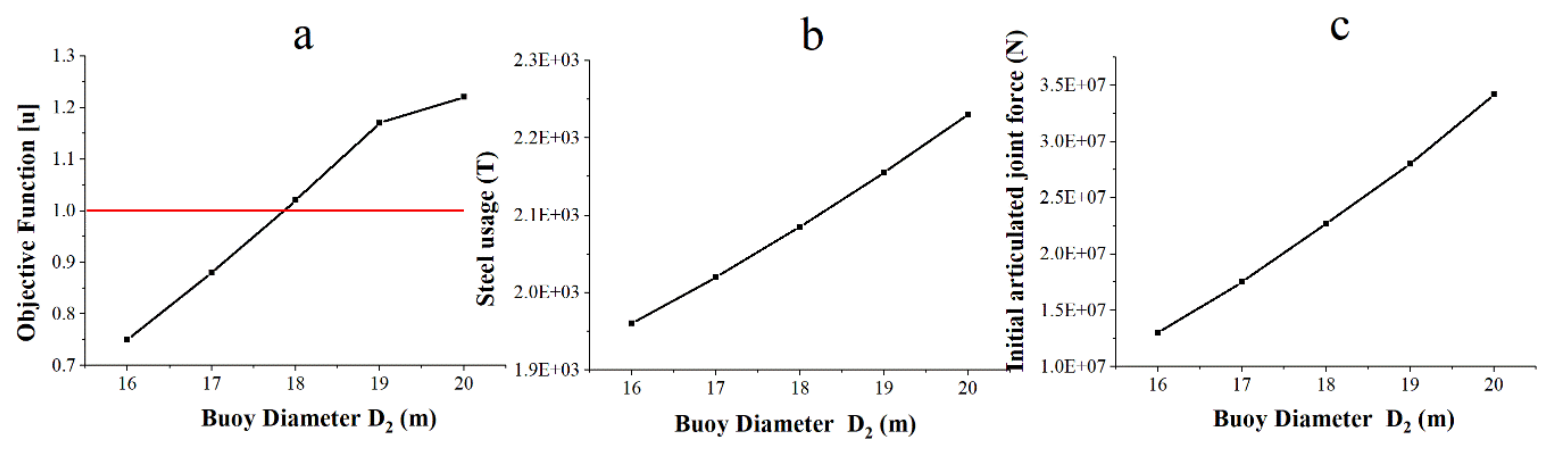

Fig. 3 Sensitivity check on $\mathrm{D}_{2}$ 

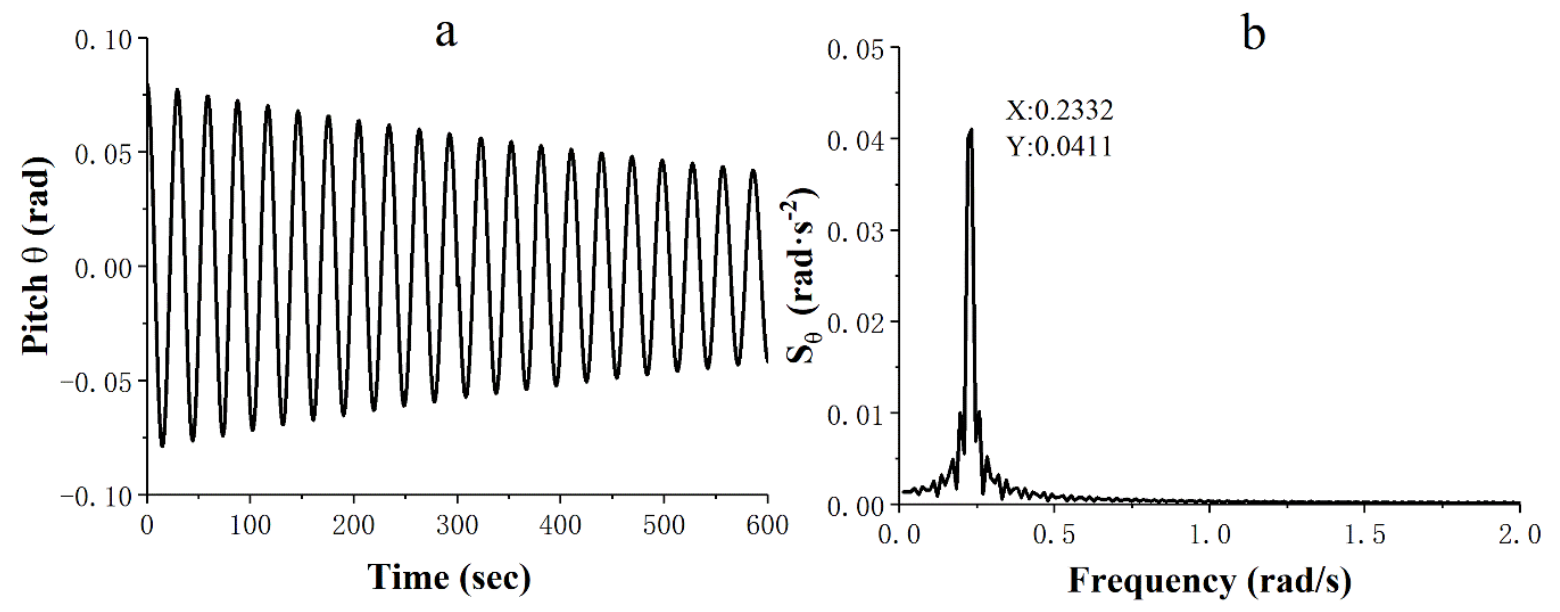

Fig. 4 Free decay simulation results 


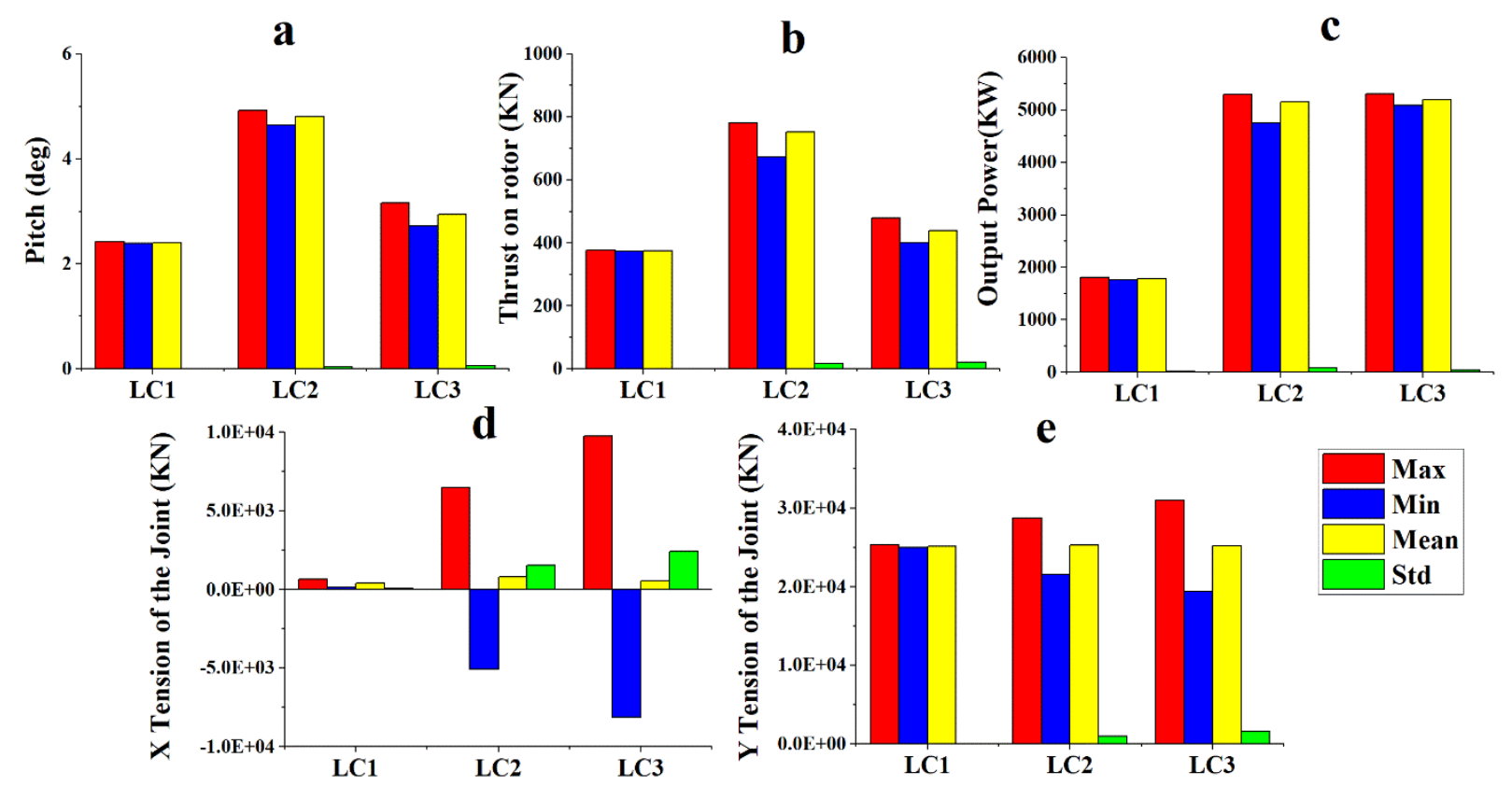

Fig. 5 Statistic results of motions, aerodynamic performance and hinged joint tensions 
a

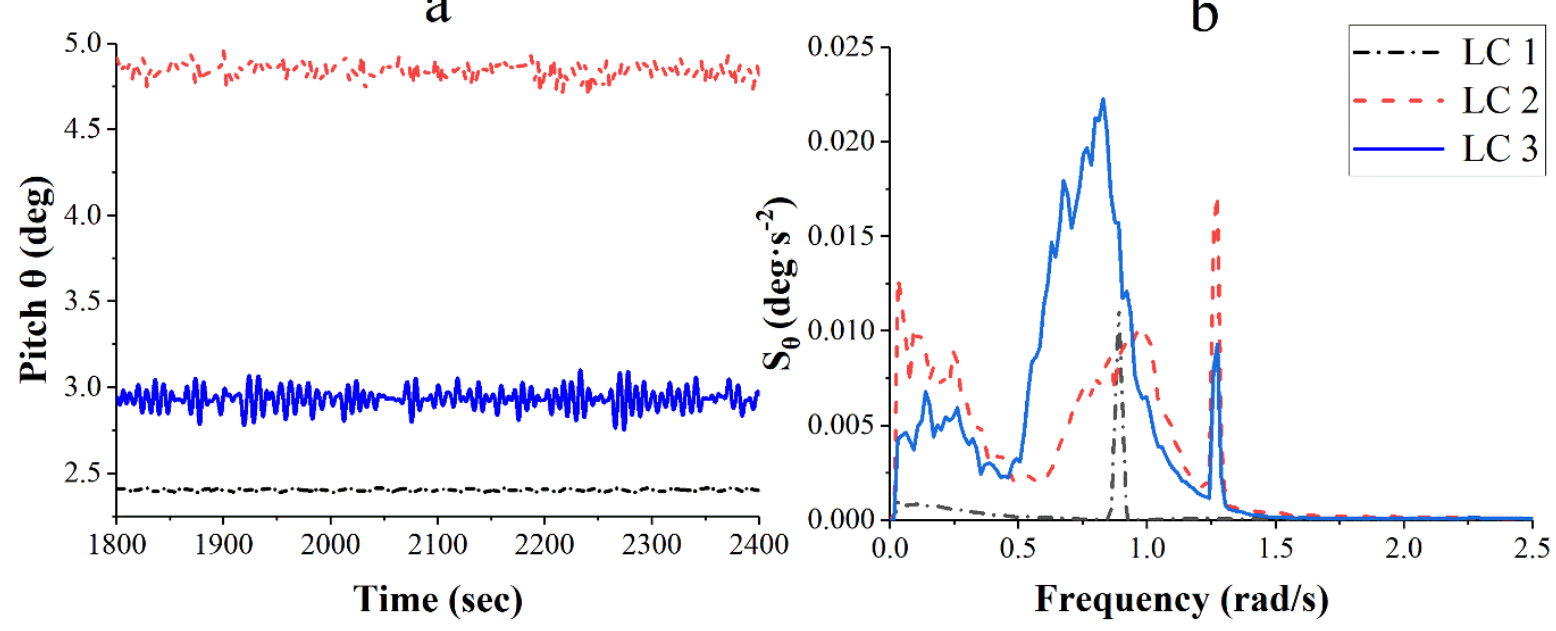

Fig. 6 Dynamic response of pitch angle 


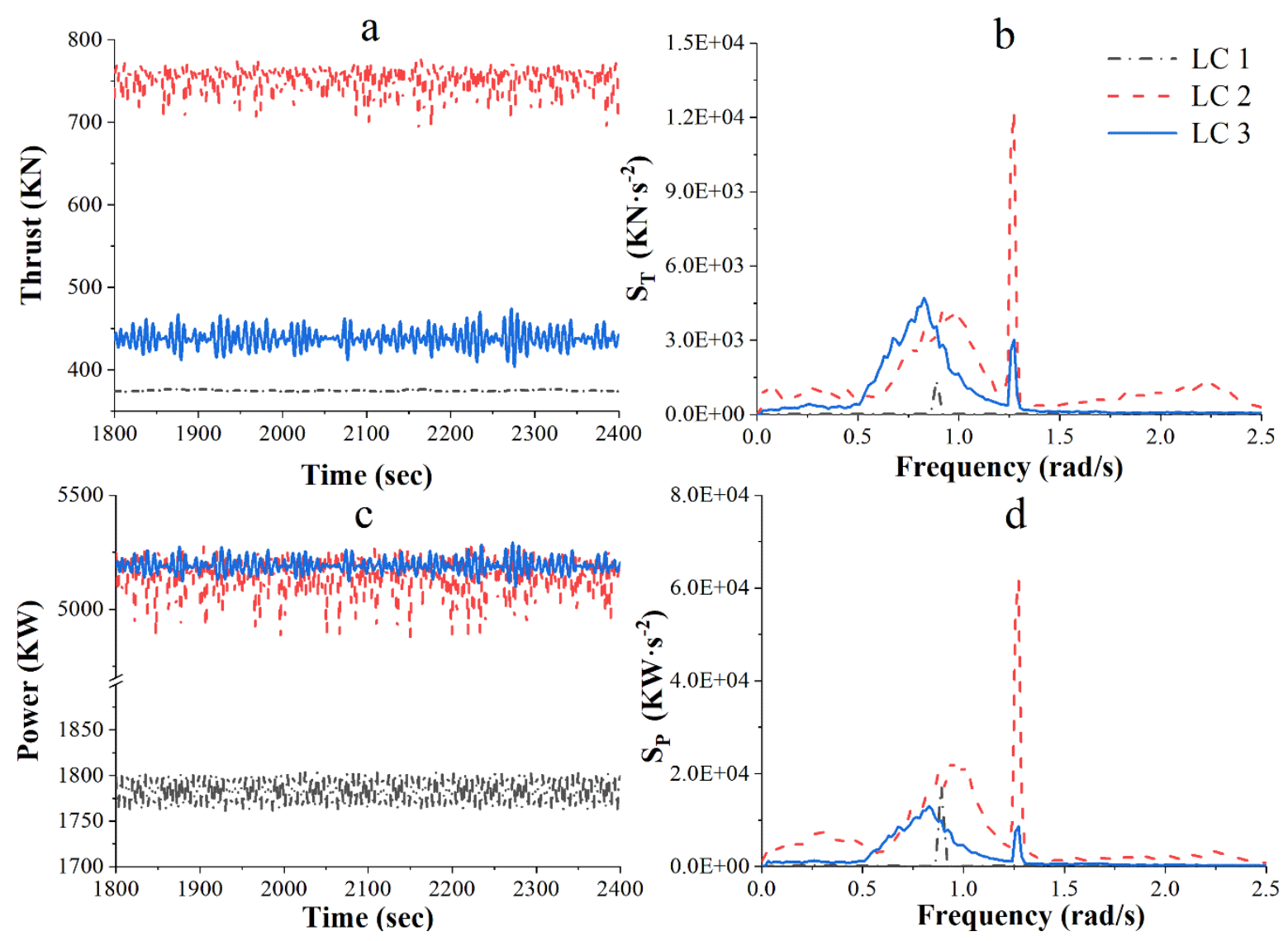

Fig. 7 Aerodynamic performance of rotor 

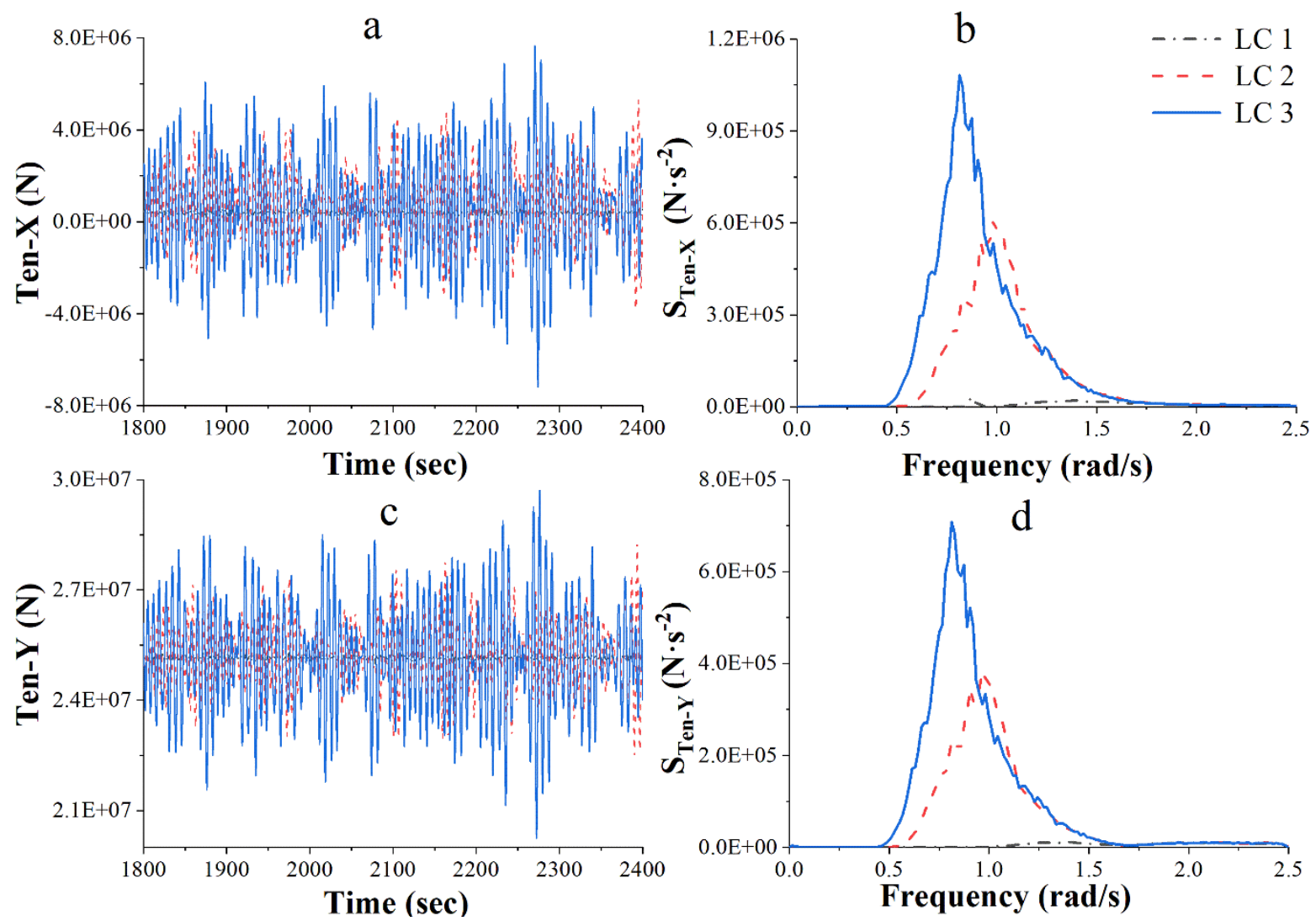

Fig. 8 Tensions on the hinged joint 
Table 1 Main parameters of the AOWT

\begin{tabular}{cc}
\hline \hline Parameter & Value \\
\hline Design water depth & $75 \mathrm{~m}$ \\
Ballast Tank Diameter, height & $9 \mathrm{~m}, 20 \mathrm{~m}$ \\
Middle Column Diameter, height & $6 \mathrm{~m}, 25 \mathrm{~m}$ \\
Buoyancy Tank Diameter, height & $18 \mathrm{~m}, 20 \mathrm{~m}$ \\
Upper Column Diameter, height & $6 \mathrm{~m}, 10 \mathrm{~m}$ \\
Steel thickness & $0.07 \mathrm{~m}$ \\
Total mass & $5195109 \mathrm{~kg}$ \\
Center of Gravity (Whole) & $(0.0 \mathrm{~m}, 0.0 \mathrm{~m}, 40.87 \mathrm{~m})$ \\
Buoyancy & $7769800 \mathrm{~kg}$ \\
Center of Buoyancy & $(0.0 \mathrm{~m}, 0.0 \mathrm{~m}, 46.91 \mathrm{~m})$ \\
Overall inertia & $1.88 \mathrm{e} 10 \mathrm{~kg} \cdot \mathrm{m}^{2}$ \\
Initial tension on hinge & $2.51 \mathrm{e} 7 \mathrm{~N}$ \\
\hline \hline
\end{tabular}


Table 2 List of scenarios

\begin{tabular}{cccccc}
\hline \hline Load case & $\begin{array}{c}\text { Wind velocity } \\
(\mathrm{m} / \mathrm{s})\end{array}$ & $\begin{array}{c}\text { Gen Speed } \\
(\mathrm{rpm})\end{array}$ & $\begin{array}{c}\text { Wave height } \\
(\mathrm{m})\end{array}$ & $\begin{array}{c}\text { Peaked period } \\
(\mathrm{s})\end{array}$ & $\begin{array}{c}\text { Current velocity } \\
(\mathrm{m} / \mathrm{s})\end{array}$ \\
\hline 1 & 8.0 & 8.5 & 1.0 & 3.5 & 0.2 \\
2 (Rated) & 11.4 & 12.1 & 3.0 & 6.3 & 0.4 \\
3 & 15.0 & 12.1 & 4.0 & 7.4 & 0.6 \\
\hline \hline
\end{tabular}

